\title{
Decreased VEGF-A and sustained PEDF expression in a human retinal pigment epithelium cell line cultured under hypothermia
}

\author{
Masayuki Takeyama' ${ }^{1}$, Masahiko Yoneda², Masahiko Gosho ${ }^{3}$, Masayoshi Iwaki and Masahiro Zako ${ }^{1 *}$
}

\begin{abstract}
Background: Previous reports have described a decrease in retinal temperature and clinical improvement of wet age-related macular degeneration (AMD) after vitrectomy. We hypothesized that the retinal temperature decrease after vitrectomy plays a part in the suppression of wet AMD development. To test this hypothesis, we evaluated the temperature dependence of the expression of vascular endothelial growth factor-A (VEGF-A) and in vitro angiogenesis in retinal pigment epithelium (RPE).
\end{abstract}

Results: We cultured ARPE-19 cells at $37,35,33$ and $31^{\circ} \mathrm{C}$ and measured the expression of VEGF-A, VEGF-A splicing variants, and pigment epithelium-derived factor (PEDF). We performed an in vitro tube formation assay. The dehydrogenase activity was also evaluated at each temperature. Expression of VEGF-A significantly decreased with decreased temperature while PEDF expression did not. VEGF165 expression and in vitro angiogenesis also were temperature dependent. The dehydrogenase activity significantly decreased as the culture temperature decreased.

Conclusions: RPE cultured under hypothermia that decreased cellular metabolism also had decreased VEGF-A and sustained PEDF expression, creating an anti-angiogenic environment. This mechanism may be associated with a beneficial effect after vitrectomy in patients with wet AMD.

Keywords: Age-related macular degeneration (AMD), Hypothermia, Pigment epithelium-derived factor (PEDF), Retinal pigment epithelium (RPE), Vascular endothelial growth factor (VEGF), Vitrectomy

\section{Background}

Previous reports have shown that wet age-related macular degeneration (AMD) improves clinically after vitrectomy, even though the primary pathogenesis in wet AMD occurs in the outer retina, including the retinal pigment epithelium (RPE), Bruch's membrane, and choroid [1-5]. Secretion by the RPE of vascular endothelial growth factor-A (VEGF-A), which acts as an angiogenic molecule in the retina, plays a critical role in the development of wet AMD [6-9]. Vitreous oxygenation, vitreoretinal traction removal, and diffusion of vitreous substances are assumed to contribute to the beneficial effects [10-12];

\footnotetext{
*Correspondence: zako@aichi-med-u.ac.jp

${ }^{1}$ Department of Ophthalmology, Aichi Medical University,

Nagakute 480-1195, Aichi, Japan

Full list of author information is available at the end of the article
}

however, the precise mechanism by which vitrectomy affects wet AMD is still unclear.

The intraocular temperature is influenced by the temperature of the outside air and modified by intraocular surgery. The temperature within the anterior chamber is most affected by the outside air. Romano et al. measured and compared intraocular temperatures during surgery and found that the temperature within the anterior chamber was $23.6^{\circ} \mathrm{C}$ [13]. The retinal temperatures immediately adjacent to the fovea before and after vitrectomy were 34.9 and $32.6^{\circ} \mathrm{C}$, respectively [14]. Retinal temperature just after vitrectomy is $2.3^{\circ} \mathrm{C}$ lower than before vitrectomy with the eyelid open, suggesting that the difference may be induced by cooling mediated by outside air and an anatomical alteration in the vitreous cavity after vitrectomy. 
This decrease in retinal temperature after vitrectomy may have a beneficial effect on wet AMD. It was previously shown that secretion of VEGF-A by RPE at $34^{\circ} \mathrm{C}$ was decreased compared with secretion by cells grown at $37^{\circ} \mathrm{C}$ [15]; however, that study compared VEGF-A secretion only at the two temperatures, which might not give a complete overview of changes in VEGF-A expression at various temperatures that are clinically relevant after vitrectomy. Here we cultured RPE at 37, 35, 33 , and $31^{\circ} \mathrm{C}$ and measured the expression of VEGF-A, VEGF-A splicing variants, and placental growth factor (PlGF). Furthermore, we measured the expression of pigment epithelium-derived factor (PEDF), which is a major angiogenesis inhibitor in retina $[6,16-18]$. To investigate differences that may occur in the angiogenic environment upon temperature variation, we also performed an in vitro tube formation assay using the conditioned medium collected after culture at each temperature. Dehydrogenase activity was measured to evaluate cellular metabolism at each temperature. Finally, our results support the hypothesis that the continuous mild hypothermia of retina achieved after vitrectomy may have a beneficial effect in wet AMD.

\section{Results and discussion VEGF-A}

VEGF-A mRNA expression was measured by real-time PCR. In samples collected after $24 \mathrm{~h}$, the mRNA expression measured at lower temperatures was decreased compared to expression in cells cultured at $37^{\circ} \mathrm{C}$, with an observed decrease of $14.8 \%$ at $35^{\circ} \mathrm{C}, 39.3 \%$ at $33^{\circ} \mathrm{C}$, and $43.3 \%$ at $31^{\circ} \mathrm{C}$. In samples collected after $48 \mathrm{~h}$, compared with cells cultured at $37^{\circ} \mathrm{C}$, the decreases measured at each reduced temperature were $35^{\circ} \mathrm{C}, 37.3 \%$; $33^{\circ} \mathrm{C}, 52.0 \%$; and $31^{\circ} \mathrm{C}, 59.3 \%$. This temperature-dependent decrease was statistically significant (Fig. 1a, left).

VEGF-A protein concentration in the conditioned medium was measured by enzyme-linked immunosorbent assay (ELISA). In samples collected after $24 \mathrm{~h}$, the decreases measured at each reduced temperature compared to $37^{\circ} \mathrm{C}$ were as follows: $35^{\circ} \mathrm{C}, 9.55 \% ; 33^{\circ} \mathrm{C}, 25.3 \%$; and $31^{\circ} \mathrm{C}, 46.6 \%$. In samples collected after $48 \mathrm{~h}$, the
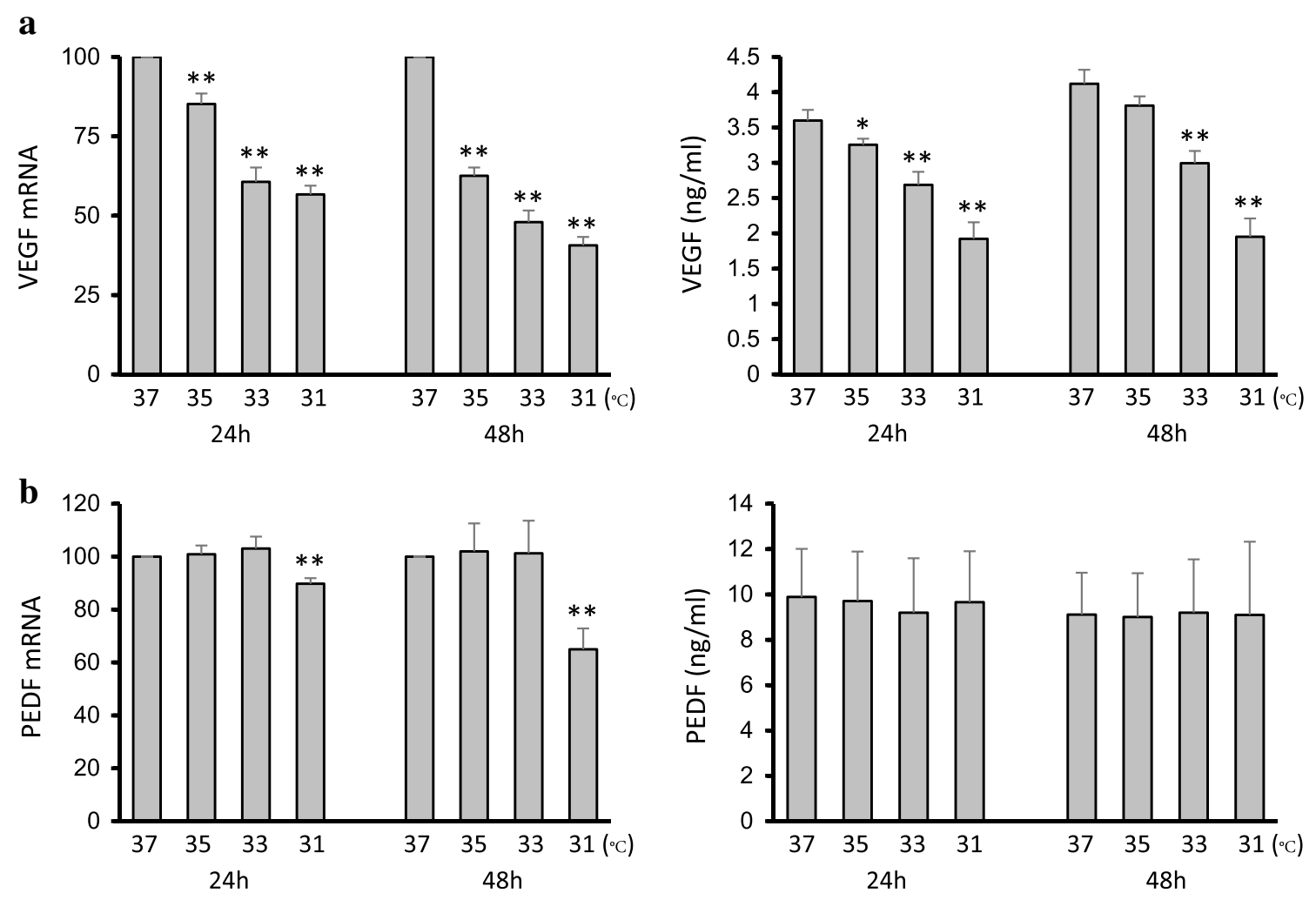

Fig. 1 Temperature-dependent decrease in VEGF-A expression and sustained, temperature-independent PEDF expression in ARPE-19 cells. Expression of mRNA and protein abundance were measured by real-time PCR and ELISA, respectively. a VEGF-A expression showed a statistically significant temperature-dependent decrease. $\mathbf{b}$ PEDF expression showed no significant change within the temperature range from 37 to $31^{\circ} \mathrm{C}$, with the exception of $\mathrm{mRNA}$ at $31^{\circ} \mathrm{C}$. Data are shown as mean $\pm \mathrm{SD}(n=4) .{ }^{*} \mathrm{P}<0.05$, ${ }^{* *} \mathrm{P}<0.01$. 
decreases measured at each reduced temperature were $35^{\circ} \mathrm{C}, 7.52 \%$; $33^{\circ} \mathrm{C}, 27.3 \%$; and $31^{\circ} \mathrm{C}, 52.6 \%$. Significant temperature-dependent decreases in protein abundance were also observed (Fig. 1a, right). Overall, expression of both VEGF-A mRNA and protein decreased as the culture temperature decreased in samples collected after either 24 or $48 \mathrm{~h}$.

\section{PEDF}

PEDF mRNA expression was measured by real-time PCR. In samples collected after $24 \mathrm{~h}$, no significant change in PEDF mRNA expression was found over the range from $37-33^{\circ} \mathrm{C}$. However, PEDF mRNA expression at $31^{\circ} \mathrm{C}$ was significantly lower than at $37^{\circ} \mathrm{C}$. Similarly, in samples collected after $48 \mathrm{~h}$, no significant expression change was found over the range from $37-33^{\circ} \mathrm{C}$, but at $31^{\circ} \mathrm{C}$, expression significantly decreased by $45.0 \%$ compared with expression in cells cultured at $37^{\circ} \mathrm{C}$ (Fig. $1 \mathrm{~b}$, left). The concentration of PEDF protein in the conditioned medium was measured by ELISA. PEDF protein abundance showed no significant change over the range of $37-31^{\circ} \mathrm{C}$ (Fig. 1b, right).

\section{VEGF165}

VEGF165 expression in conditioned medium was measured by western blot analysis, and the results are shown in Fig. 2. In samples collected after $24 \mathrm{~h}$, decreased expression was observed at all temperatures compared to expression at $37^{\circ} \mathrm{C}$, with a percent decrease of $10.7 \%$ at $35^{\circ} \mathrm{C} ; 12.7 \%$ at $33^{\circ} \mathrm{C}$; and $39.9 \%$ at $31^{\circ} \mathrm{C}$. In samples collected after $48 \mathrm{~h}$, the corresponding decreases were $35^{\circ} \mathrm{C}$, $6.41 \% ; 33^{\circ} \mathrm{C}, 15.7 \%$; and $31^{\circ} \mathrm{C}, 42.3 \%$. Expression at $31^{\circ} \mathrm{C}$ was significantly decreased in samples collected after 24 and $48 \mathrm{~h}$. Generally, expression was observed to decrease in a temperature-dependent fashion.

\section{VEGF121}

VEGF121 expression was not detected by western blot analysis in any of the samples examined (Fig. 2a).

\section{PIGF}

PlGF expression was not detected by real-time PCR or ELISA in any of the samples examined (data not shown).

\section{Tube formation assay}

To investigate possible changes in the angiogenic environment produced by RPE, we performed endothelial tube formation (in vitro angiogenesis) assays using conditioned medium from ARPE-19 cells cultured at various temperatures, from 37 to $31^{\circ} \mathrm{C}$, and for either 24 or $48 \mathrm{~h}$. Representative photomicrographs and image

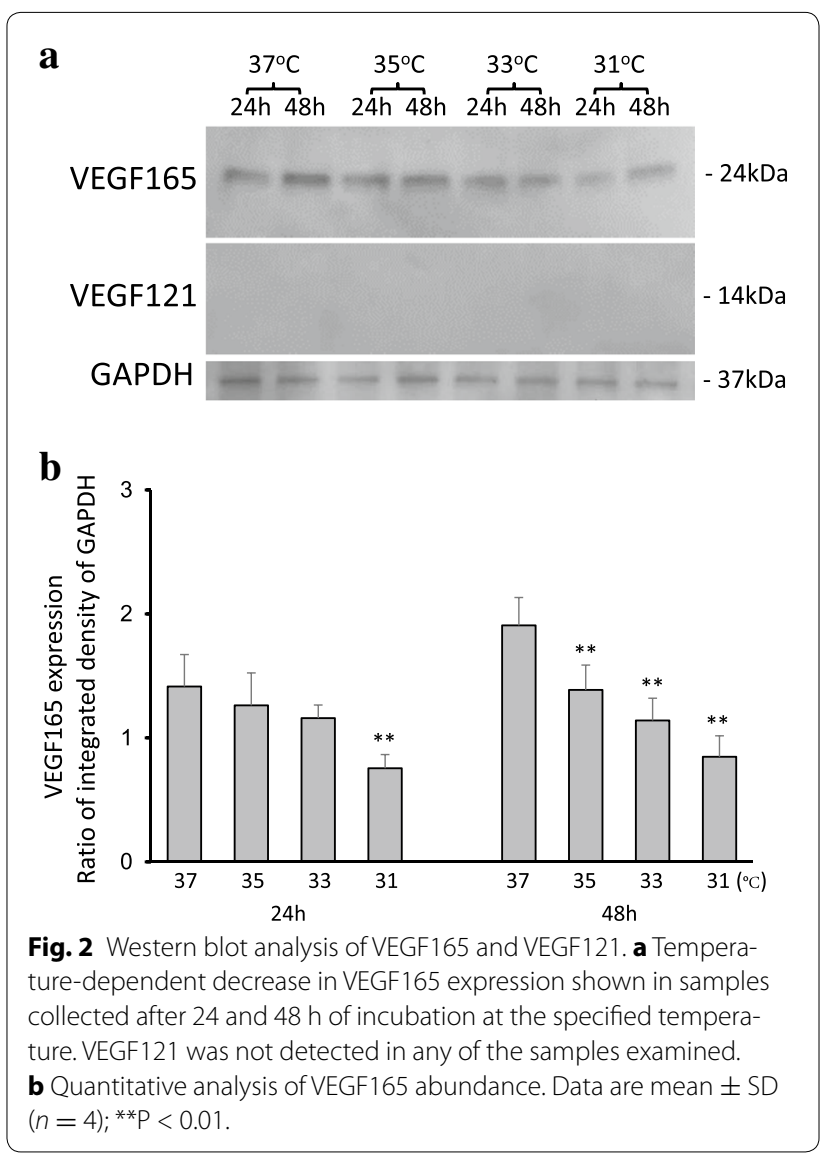

quantitative analysis are shown in Fig. 3. Typical tube formation was not found in any of the samples. However, significant differences in the number of branching points and total skeleton length were observed among the conditions. With conditioned medium samples collected after $24 \mathrm{~h}$, the number of branching points was reduced compared to the values observed at $37^{\circ} \mathrm{C}$ by the following percentages: at $35^{\circ} \mathrm{C}, 26.6 \%$; at $33^{\circ} \mathrm{C}, 56.5 \%$; and at $31^{\circ} \mathrm{C}, 60.9 \%$. In samples collected after $48 \mathrm{~h}$, the percent decrease in expression was as follows: at $35^{\circ} \mathrm{C}$, $47.1 \%$; at $33^{\circ} \mathrm{C}, 61.7 \%$; and at $31^{\circ} \mathrm{C}, 73.8 \%$. With respect to total skeleton length, in samples collected after $24 \mathrm{~h}$ and compared with conditioned medium from cells cultured at $37^{\circ} \mathrm{C}$ as the baseline, the decreases observed at each temperature were as follows: at $35^{\circ} \mathrm{C}, 19.3 \%$; at $33^{\circ} \mathrm{C}, 44.6 \%$; and at $31^{\circ} \mathrm{C}, 80.7 \%$. In samples collected after $48 \mathrm{~h}$, the decreases observed at each temperature were as follows: at $35^{\circ} \mathrm{C}, 14.4 \%$; at $33^{\circ} \mathrm{C}, 47.1 \%$; and at $31^{\circ} \mathrm{C}, 83.6 \%$. Overall, the number of branching points and total skeleton length in samples collected after either $24 \mathrm{~h}$ or $48 \mathrm{~h}$ showed significant decreases as the culture temperature decreased. 


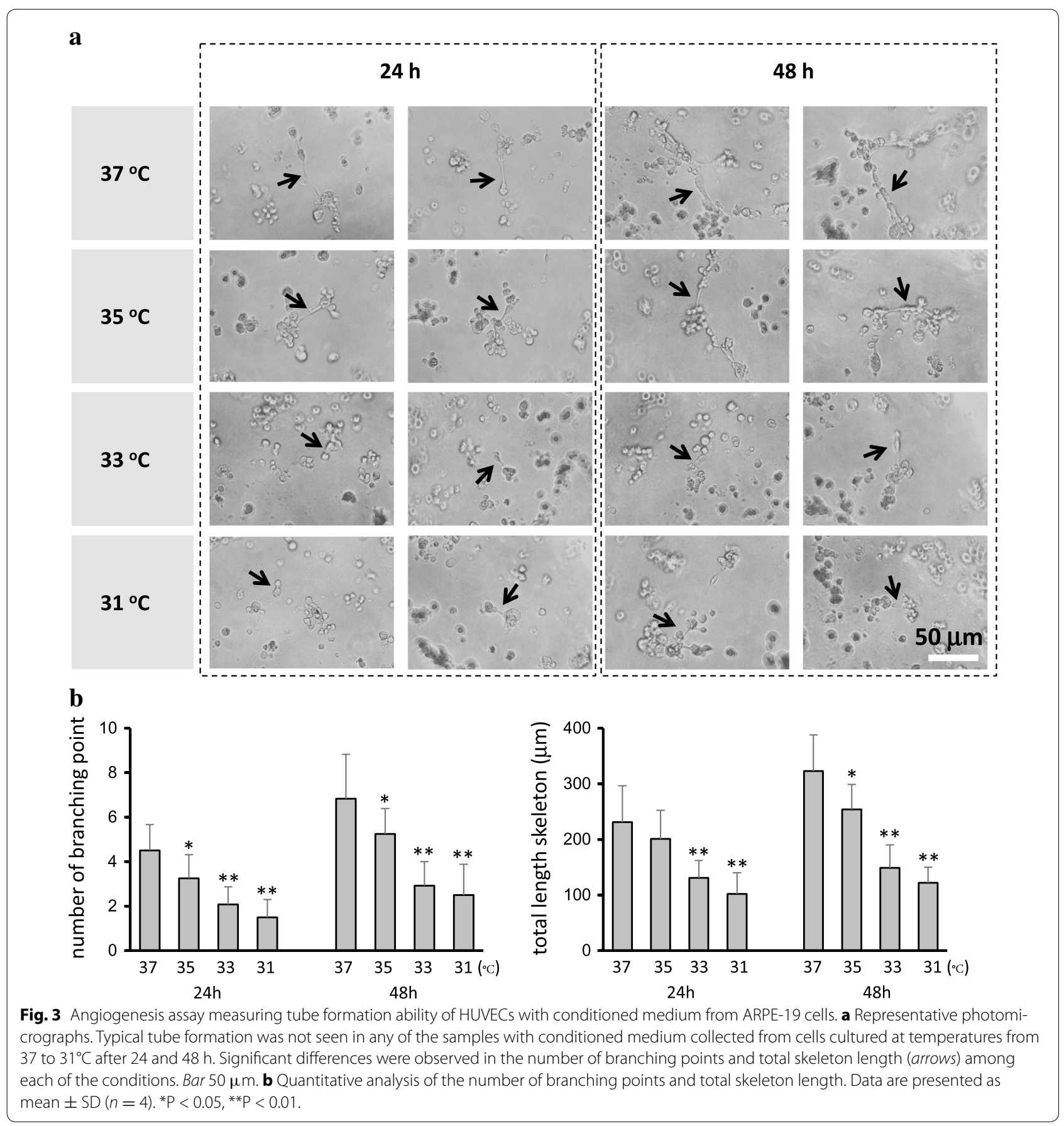

\section{Measurement of cellular metabolism}

The metabolism of cells cultured at each adjusted temperature was evaluated by dehydrogenase activity. In samples collected after incubation for $24 \mathrm{~h}$, the decreases measured at each reduced temperature compared to $37^{\circ} \mathrm{C}$ were as follows: $35^{\circ} \mathrm{C}, 12.3 \% ; 33^{\circ} \mathrm{C}, 37.8 \%$; and $31^{\circ} \mathrm{C}$, $36.0 \%$. In samples collected after incubation for $48 \mathrm{~h}$, the decreases measured at each reduced temperature were $35^{\circ} \mathrm{C}, 25.6 \%$; $33^{\circ} \mathrm{C}, 25.7 \%$; and $31^{\circ} \mathrm{C}, 52.8 \%$. Significant temperature-dependent decreases in dehydrogenase activity were observed in samples collected after either 24 or 48 h (Fig. 4).

The balance between VEGF-A and PEDF plays an important role in choroidal neovascularization $[6,16-$ 18]. In the present study, VEGF-A expression significantly decreased in RPE with temperature dependence, 


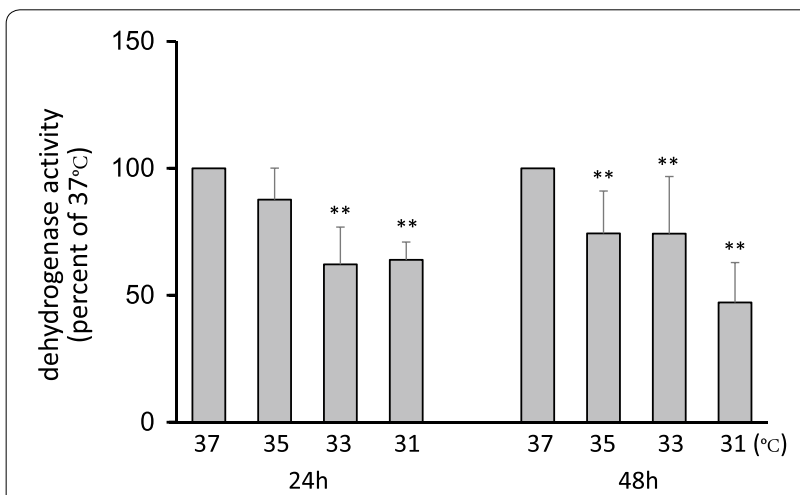

Fig. 4 Dehydrogenase activity in ARPE-19 cells at each adjusted temperature. Cellular metabolism evaluated by dehydrogenase activity significantly decreased as the culture temperature decreased. Data are presented as mean $\pm \mathrm{SD}(n=5)$; ${ }^{* * P}<0.01$.

as analyzed using real-time PCR and ELISA. Western blot analysis showed a temperature-dependent decrease in VEGF165 expression. In contrast, PEDF protein abundance did not show significant change. Thus, RPE cultured at temperatures lower than $37^{\circ} \mathrm{C}$ may exhibit an anti-angiogenic environment because of the decreased VEGF-A expression in conjunction with sustained PEDF expression. The results of the tube formation angiogenesis assay also supported this hypothesis, although typical tube formation was not observed, probably because of insufficient VEGF expression.

The sustained PEDF that is secreted from RPE predominantly to the apical side [19-22] may play a role in preventing wet AMD development by the following two mechanisms. First, because the secreted PEDF plays an autocrine role in maintaining RPE function [20], healthy RPE maintained by sufficient PEDF should prevent an invasion of choroidal neovascularization to the retinal side. Second, PEDF in the basal side, even if it is not a large amount, may act as an antagonist for VEGF-A. Becerra et al. investigated PEDF localization in monkey eye and detected PEDF not only in the apical side but also in the Bruch membrane [21].

The measurement of dehydrogenase activity at each adjusted temperature showed a cellular metabolism decrease in association with the culture temperature decrease. We confirmed no significant difference in the number of cells in the dish at the end of incubation between each sample (data not shown). This result implies that a decrease in VEGF-A expression is correlated with a decrease in metabolism in cells cultured under hypothermia, although it is still unclear why PEDF expression is not so closely correlated.

The retinal temperature in a vitrectomized eye is lower than that in a non-vitrectomized eye, but this measurement of real-time retinal temperature in humans may be possible only during surgery. The anterior chamber temperature is remarkably cooled [13], and ophthalmologists often observe a warm current of aqueous humor convective flow caused by cooling of the anterior chamber by outside air. Because of thermal diffusion from the posterior to the anterior chamber through the lens, the anterior vitreous cavity temperature may be lower than the posterior vitreous cavity temperature. In the vitreous cavity not filled with viscous vitreous in a vitrectomized eye, a more convective flow may occur because of the difference in temperature between the anterior and posterior vitreous cavities; however, because of the viscous vitreous in a non-vitrectomized eye, such a convective flow may not easily occur. Our hypothesis regarding this intraocular thermal diffusion is shown in Fig. 5. The strict measurements taken of retinal temperature immediately adjacent to the fovea by Landers et al. during surgery were as follows: before vitrectomy, $34.9^{\circ} \mathrm{C}$; at the end of vitrectomy after plugging the sclerotomies and closing the infusion line for $5 \mathrm{~min}, 32.6^{\circ} \mathrm{C}$ [14]. This difference of $2.3^{\circ} \mathrm{C}$ may have been enough to decrease VEGF-A expression in the eye, as our present results revealed that a $2^{\circ} \mathrm{C}$ decrease caused a significant decrease in VEGF-A expression in vitro.

\section{Conclusions}

RPE cultured under hypothermia that decreased cellular metabolism exhibit decreased VEGF-A and sustained PEDF expression, creating an anti-angiogenic environment. This mechanism may be associated with a beneficial effect after vitrectomy in patients with wet AMD.

\section{Methods}

\section{RPE culture in adjusted temperature}

The human RPE cell line, ARPE-19, was obtained from the American Type Culture Collection (Manassas, VA, USA). Cultures were seeded with $5 \times 10^{5}$ cells in 35-mm culture dishes with $2 \mathrm{ml}$ of Dulbecco's minimal essential medium (Invitrogen, Carlsbad, CA, USA) containing antibiotics $(100 \mathrm{U} / \mathrm{mL}$ penicillin $\mathrm{G}$ and $100 \mathrm{mg} /$ $\mathrm{mL}$ streptomycin sulfate; Invitrogen) and $10 \%$ fetal calf serum, and grown at $37^{\circ} \mathrm{C}$ in an atmosphere of $5 \% \mathrm{CO}_{2}$. Subsequently, medium change was performed every $24 \mathrm{~h}$. At day 2, cells reached confluence. At day 3, medium was changed with $2 \mathrm{ml}$ of Dulbecco's minimal essential medium containing antibiotics and $1 \%$ fetal calf serum. At day 4, medium was changed, and cells were transferred to temperature-adjusted incubators at 37, 35, 33 and $31^{\circ} \mathrm{C}$ in an atmosphere of $5 \% \mathrm{CO}_{2}$. The ARPE-19 cell samples and conditioned media were collected at $24 \mathrm{~h}$ and $48 \mathrm{~h}$ after the start of incubation at each adjusted 


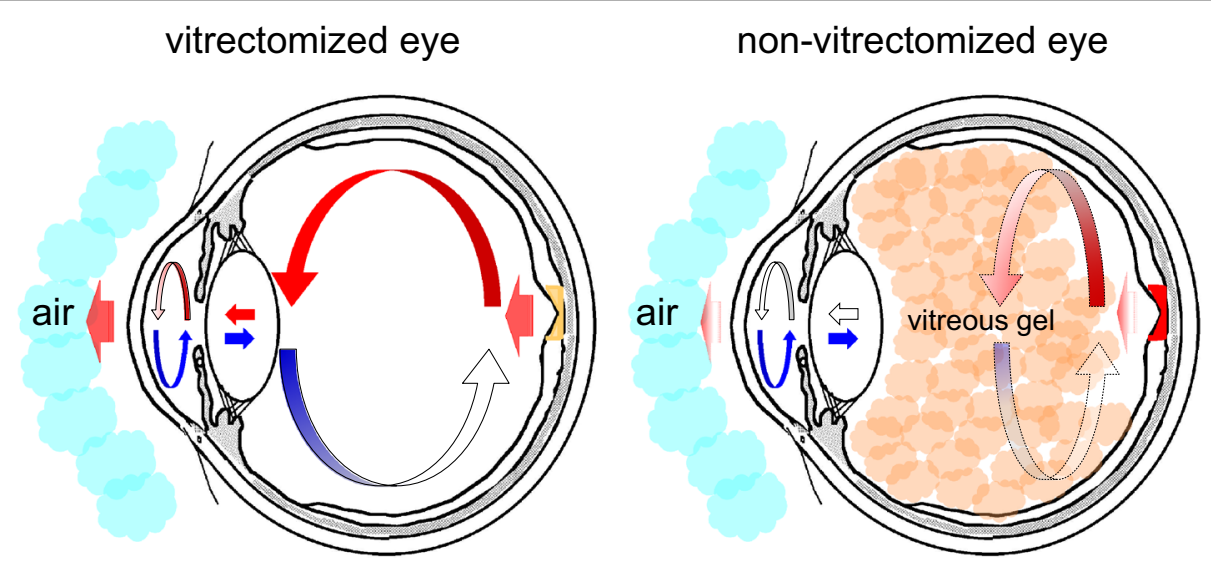

Fig. 5 Hypothetical intraocular thermal diffusion in vitrectomized and non-vitrectomized eyes. Red arrows indicate the stream of heat within the eye globe. Blue arrows represent the stream of cooling by the outside air. Because of thermal diffusion from the posterior to anterior chamber through the lens, the anterior vitreous cavity temperature may be lower than the posterior vitreous cavity temperature. In the vitrectomized eye, without viscous vitreous, a more convective flow may occur because of the difference in temperature between the anterior and posterior vitreous cavities, compared to the situation with viscous vitreous in the non-vitrectomized eye, in which a convective flow may not easily occur.

temperature. Conditioned media samples were stored at $-80^{\circ} \mathrm{C}$ until use.

\section{Real-time PCR}

Isolation of total RNA from ARPE-19 cells was performed using the SV Total RNA Isolation System (Promega, Madison, WI, USA) according to the manufacturer's instructions. Isolated total RNA was reverse transcribed to DNA using random primers using a SuperScript ${ }^{\circledR}$ VILO $^{\mathrm{TM}}$ cDNA Synthesis Kit ${ }^{\circledR}$ (Invitrogen), according to the manufacturer's instructions. Real-time PCR was performed using the Thermal Cycler Dice ${ }^{\circledR}$ Real Time System (Takara Bio Incorporated, Shiga, Japan), and SYBR ${ }^{\circledR}$ Premix Ex $\mathrm{Taq}^{\text {TM }}$ (Takara Bio Incorporated) was used for quantification of VEGF-A, PlGF, and PEDF mRNA. Thermal cycle conditions included an initial denaturation at $95^{\circ} \mathrm{C}$ for $10 \mathrm{~s}$, followed by 40 cycles of PCR amplification $\left(95^{\circ} \mathrm{C}\right.$ for $15 \mathrm{~s}, 60^{\circ} \mathrm{C}$ for $\left.1 \mathrm{~min}\right)$. The specificity of the amplification was confirmed using melting-curve analysis. Expression of the targeted mRNA was analyzed, with expression of glyceraldehyde-3-phosphate dehydrogenase (GAPDH) used for normalization. We analyzed these data with the competitive $C_{t}\left(\Delta \Delta C_{t}\right)$ method according to the manufacturer's instructions (Takara Bio Incorporated). Primer sequences are shown in Table 1.

\section{ELISA}

Assays were performed using the Quantikine human VEGF ELISA Kit (R\&D Systems, Minneapolis, MN), Quantikine human PIGF ELISA Kit (R\&D Systems), and human PEDF ELISA (BioVendor Laboratory Medicine, Inc., Modrice, Czech Republic). An aliquot of $200 \mu \mathrm{l}$ of conditioned medium was used per well.
Table 1 Primer pairs used for real-time PCR analysis

\begin{tabular}{cll}
$\begin{array}{l}\text { Gene (GenBank } \\
\text { accession no.) }\end{array}$ & Direction & $\begin{array}{l}\text { Oligonucleotide sequence } \\
\left(\mathbf{5}^{\prime} \boldsymbol{\rightarrow} \mathbf{3}^{\prime}\right)\end{array}$ \\
\hline $\begin{array}{cll}\text { VEGF-A } \\
\text { (NM_001025366) }\end{array}$ & Sense & TCACAGGTACAGGGATGAGGACAC \\
PIGF (NM_002632.5) & Sense & TCCTGGGCAACTCAGAAGCA \\
& Antisense & GAGAGAAGCAGAGACCCACAGAC \\
PEDF (NM_002615.5) & Sense & CCCATGATGTCGGACCCTAA \\
& Antisense & TGTCATGAATGAACTCGGAGGG \\
GAPDH (NM_002046) & Sense & GCACCGTCAAGGCTGAGAAC \\
& Antisense & TGGTGAAGACGCCAGTGGA \\
\hline
\end{tabular}

\section{Western blot analysis}

Conditioned medium $(10 \mu \mathrm{l})$ was mixed with sodium dodecyl sulfate gel-loading buffer. Samples were loaded onto $15 \%$ sodium dodecyl sulfate polyacrylamide gels. After electrophoresis, proteins were electro-transferred to nitrocellulose membranes and developed with goat anti-human VEGF165 polyclonal antibody (1:1,000; R\&D Systems) and polyclonal rabbit anti-goat immunoglobulins/horseradish peroxidase (HRP) (1:10,000; Dako, Denmark). The membranes were then incubated in stripping buffer (Thermo Fisher Scientific Inc., Waltham, MA), washed with phosphate-buffered saline containing $0.1 \%$ Tween-20 (Wako Pure Chemical Industries, Ltd., Osaka, Japan), and then developed a second time with rabbit anti-human VEGF121 polyclonal antibody (1:1,000; Rockland Immunochemicals, Inc., Gilbertsville, PA) and polyclonal swine anti-rabbit immunoglobulins/HRP (1:10,000; Dako). These data were normalized by GAPDH 
expression. The cells in each dish were lysed by $200 \mu \mathrm{l}$ of CelLytic M (Sigma-Aldrich, St.Louis, MO, USA), and $10 \mu \mathrm{l}$ of prepared cell lysate was used for the measurement of GAPDH expression. Polyclonal goat antiGAPDH antibody (1:1,000; Santa Cruz Biotechnology, Inc., Santa Cruz, CA, USA) was used as primary antibody, and polyclonal rabbit anti-goat immunoglobulin/ HRP (1:10,000; Dako) was used as secondary antibody. All western blots were finally developed by HRP with the detection reagent Western Lightning Plus ECL (PerkinElmer Inc., Waltham, MA). Band densities were quantified using ImageJ software (National Institute of Health, http://rsb.info.nih.gov/ij/).

\section{Tube formation assay}

To examine the angiogenic environment produced by RPE, we performed in vitro tube formation assays using an in vitro angiogenesis assay kit (Merck Millipore, Billerica, MA, USA). The 96-well assay plate was prepared according to the manufacturer's instructions. Human umbilical cord vein endothelial cells (HUVEC, Lonza, Basel, Switzerland, No. CC-2517) were plated $\left(2.0 \times 10^{4}\right.$ cells/well) with $150 \mu \mathrm{l}$ of the conditioned medium in a prepared 96-well plate, incubated at $37^{\circ} \mathrm{C}$ for $5 \mathrm{~h}$, and photographed (field/well) under the microscope. On six photographs in each group, two independent observers manually counted the number of branching points and measured the length of the skeleton structure.

\section{Measurement of cellular metabolism}

To investigate the metabolism of cells cultured at each adjusted temperature, we measured the dehydrogenase activity, which reflects cellular metabolism. ARPE-19 cells at $1 \times 10^{4}$ cells/well were seeded in a 96-well plate with $100 \mu \mathrm{l}$ of medium, and the schedule of medium changes was the same as described above. At the end of the culture period, the dehydrogenase activity was measured using a Cell Counting Kit-8 (Dojindo Laboratories, Kumamoto, Japan). According to the manufacturer's instructions, we assumed the $450 \mathrm{~nm}$ absorbance as an index of the dehydrogenase activity.

\section{Statistical analysis}

Experiments were repeated four times. The results are presented as the mean \pm standard deviation (SD). Comparison of more than two groups was performed using analysis of variance, including temperature as a factor, with Dunnett's test to adjust for multiplicity. The value measured at $37^{\circ} \mathrm{C}$ was defined as the control. We used SAS 9.3 software (SAS Institute, Cary, NC, USA) for all statistical analyses. Differences with $P$ values $<0.05$ were considered significant.

\section{Abbreviations}

AMD: age-related macular degeneration; ELISA: enzyme-linked immunosorbent assay; GAPDH: glyceraldehyde-3-phosphate dehydrogenase; HUVEC: human umbilical cord vein endothelial cell; PIGF: placental growth factor; PEDF: pigment epithelium-derived factor; RPE: retinal pigment epithelium; VEGF-A: vascular endothelial growth factor-A.

\section{Authors' contributions}

MT and MY designed this study and carried out the experiments. MG analyzed the data. MT drafted the manuscript. MI revised the manuscript. MZ was a major contributor in designing, writing, and revising the manuscript. All authors approved the final manuscript.

\section{Author details}

1 Department of Ophthalmology, Aichi Medical University, Nagakute 480-1195, Aichi, Japan. ${ }^{2}$ Department of Biochemistry and Molecular Biology, School of Nursing and Health, Aichi Prefectural University, Nagoya 463-8502, Aichi, Japan. ${ }^{3}$ Department of Clinical Trial and Clinical Epidemiology, Faculty of Medicine, University of Tsukuba, Tsukuba 305-8575, Ibaraki, Japan.

\section{Acknowledgements}

This study was supported by JSPS KAKENHI Grant Number 25861659, and Strategic Research Foundation Grant-Aided Project for Private Universities from the Ministry of Education, Culture, Sports, Science, and Technology, Japan (MEXT), 2011-2015 (S1101027). The authors thank Yoshiko Takahashi for excellent technical help and Takuya Kataoka for valuable suggestions on this study.

\section{Compliance with ethical guidelines}

\section{Competing interests}

The authors declare that they have no competing interest.

Received: 27 December 2014 Accepted: 21 July 2015

Published online: 30 July 2015

\section{References}

1. Ikeda T, Sawa H, Koizumi K, Yasuhara T, Yamasaki T. Pars plana vitrectomy for regression of choroidal neovascularization with age-related macular degeneration. Acta Ophthalmol Scand. 2000;78:460-4.

2. Mojana F, Cheng L, Bartsch DU, Silva GA, Kozak I, Nigam N, et al. The role of abnormal vitreomacular adhesion in age-related macular degeneration: spectral optical coherence tomography and surgical results. Am J Ophthalmol. 2008;146:218-27.

3. Sakamoto T, Sheu SJ, Arimura N, Sameshima S, Shimura M, Uemura A, et al. Vitrectomy for exudative age-related macular degeneration with vitreous hemorrhage. Retina. 2010;30:856-64.

4. Roller AB, Mahajan VB, Boldt HC, Abramoff MD, Russell SR, Folk JC. Effects of vitrectomy on age-related macular degeneration. Ophthalmology. 2010;117:1381-6.

5. Schulze S, Neugebauer A, Kroll P. Appearance of age-related macular degeneration in vitrectomized and nonvitrectomized eyes: an intraindividual case study. Acta Ophthalmol. 2012;90:244-7.

6. Tombran-Tink J. PEDF in angiogenic eye diseases. Curr Mol Med. 2010;10:267-78.

7. Frank RN, Amin RH, Eliott D, Puklin JE, Abrams GW. Basic fibroblast growth factor and vascular endothelial growth factor are present in epiretinal and choroidal neovascular membranes. Am J Ophthalmol. 1996;122:393-403.

8. Ambati J, Fowler BJ. Mechanisms of age-related macular degeneration. Neuron. 2012;75:26-39.

9. Bhutto I, Lutty G. Understanding age-related macular degeneration (AMD): relationships between the photoreceptor/retinal pigment epithelium/Bruch's membrane/choriocapillaris complex. Mol Aspects Med. 2012;33:295-317.

10. Stefánsson E. Physiology of vitreous surgery. Graefes Arch Clin Exp Ophthalmol. 2009;247:147-63. 
11. Simpson AR, Petrarca R, Jackson TL. Vitreomacular adhesion and neovascular age-related macular degeneration. Surv Ophthalmol. 2012;57:498-509.

12. Schulze S, Hoerle S, Mennel S, Kroll P. Vitreomacular traction and exudative age-related macular degeneration. Acta Ophthalmol. 2008;86:470-81.

13. Romano MR, Vallejo-Garcia JL, Romano V, Angi M, Vinciguerra $P$, Costagliola C. Thermodynamics of vitreoretinal surgery. Curr Eye Res. 2013;38:371-4.

14. Landers MB 3rd, Watson JS, Ulrich JN, Quiroz-Mercado H. Determination of retinal and vitreous temperature in vitrectomy. Retina. 2012;32:172-6.

15. Coassin M, Duncan KG, Bailey KR, Singh A, Schwartz DM. Hypothermia reduces secretion of vascular endothelial growth factor by cultured retinal pigment epithelial cells. Br J Ophthalmol. 2010;94:1678-83.

16. Ohno-Matsui K, Morita I, Tombran-Tink J, Mrazek D, Onodera M, Uetama T, et al. Novel mechanism for age-related macular degeneration: an equilibrium shift between the angiogenesis factors VEGF and PEDF. J Cell Physiol. 2001;189:323-33.

17. Dawson DW, Volpert OV, Gillis P, Crawford SE, Xu H, Benedict W, et al. Pigment epithelium-derived factor: a potent inhibitor of angiogenesis. Science. 1999;285:245-8.
18. Barnstable CJ, Tombran-Tink J. Neuroprotective and antiangiogenic actions of PEDF in the eye: molecular targets and therapeutic potential. Prog Retin Eye Res. 2004;23:561-77.

19. Tombran-Tink J, Shivaram SM, Chader GJ, Johnson LV, Bok D. Expression, secretion, and age-related downregulation of pigment epithelium-derived factor, a serpin with neurotrophic activity. J Neurosci. 1995;15:4992-5003.

20. Ablonczy Z, Prakasam A, Fant J, Fauq A, Crosson C, Sambamurti K. Pigment epithelium-derived factor maintains retinal pigment epithelium function by inhibiting vascular endothelial growth factor-R2 signaling through gamma-secretase. J Biol Chem. 2009;284:30177-86.

21. Becerra SP, Fariss RN, Wu YQ, Montuenga LM, Wong P, Pfeffer BA. Pigment epithelium-derived factor in the monkey retinal pigment epithelium and interphotoreceptor matrix: apical secretion and distribution. Exp Eye Res. 2004;78:223-34

22. Maminishkis A, Chen S, Jalickee S, Banzon T, Shi G, Wang FE, et al. Confluent monolayers of cultured human fetal retinal pigment epithelium exhibit morphology and physiology of native tissue. Invest Ophthalmol Vis Sci. 2006:47:3612-24.

\section{Submit your next manuscript to BioMed Central and take full advantage of:}

- Convenient online submission

- Thorough peer review

- No space constraints or color figure charges

- Immediate publication on acceptance

- Inclusion in PubMed, CAS, Scopus and Google Scholar

- Research which is freely available for redistribution

Submit your manuscript at

www.biomedcentral.com/submit

O) BioMed Central 